\title{
VULNERABILIDADE AMBIENTAL DAS ÁREAS ALTAS DA BACIA HIDROGRÁFICA DO MUNICÍPIO DE TAQUARITINGA - SP
}

\author{
ENVIRONMENTAL VULNERABILITY OF E UPPER AREAS OF THE \\ HYDROGRAPHIC BASIN IN THE CITY OF TAQUARITINGA - SP
}

\author{
Gilberto Aparecido Rodrigues ${ }^{\mathrm{I}}$ \\ Maria Aparecida Bovério II \\ Kátia Cristina Galatti ${ }^{\mathrm{III}}$
}

\begin{abstract}
RESUMO
O estudo de vulnerabilidades ambientais em uma dada bacia hidrográfica, em particular em ambiente rural, tem por principal objetivo orientar produtores rurais e gestores urbanos da importância da situação em que se encontram os diferentes elementos da paisagem rural e, dependendo do grau de intensidade de vulnerabilidade, atitudes mitigatórias precisam ser implementadas para garantir a sustentabilidade do ambiente e dos sistemas de produção nessas áreas. O presente trabalho teve por objetivo avaliar visualmente as vulnerabilidades ambientais de uma dada área amostral, localizada em área mais alta da bacia hidrográfica de Taquaritinga - SP - Brasil, através de observação de imagens de satélite pelo Software livre Google Earth Pro. Os resultados apontaram que o uso das ferramentas do Google Earth Pro permitiu determinar com relativa precisão os elementos da paisagem e inferir um grau de vulnerabilidade da região sob estudo. Através das imagens de satélite verificou-se que a atividade de ocupação do solo tem predomínio da cultura da cana de açúcar ( $71 \%$ da área). Quanto à cobertura vegetal, constatou-se que as áreas de preservação permanente (APP) corresponderam a 4,50\% da área amostrada. Constatou-se também que as áreas de reserva legal (RL) apresentaram-se rarefeitas, assim como a presença de lâminas d'água e a presença humana no ambiente rural, determinadas por poucas construções rurais na área amostrada. Os resultados sugerem uma atenção maior do poder público no sentido de se fazer uma intervenção planejada para mitigar as vulnerabilidades visualmente em curso, principalmente pelo fato da área estar sobre uma área de recarga do aquífero Bauru.
\end{abstract}

Palavras-chave: Risco Ambiental. Geotecnologias. Paisagem rural. Elementos da paisagem

\begin{abstract}
The study of environmental vulnerabilities in a given hydrographic basin, particularly in a rural environment, has the main objective to guide rural producers and urban managers about

\footnotetext{
I Pesquisador e Docente do Curso Superior em Tecnologia em Agronegócio, Fatec Taquaritinga, São Paulo, Brasil, e-mail: gilberto.rodrigues@fatectq.edu.br

II Pós-Doutorado em Educação (UNESP-Rio Claro), Doutorado, Mestrado e Especialização em Educação (UNESP-Araraquara), Bacharel em Letras (Centro Universitário Moura Lacerda-Ribeirão Preto). Docente e pesquisadora da Faculdade de Tecnologia (Fatec) - Câmpus de Sertãozinho e Jaboticabal. Membro do Grupo de Estudos e Pesquisas em Políticas e Gestão da Educação Superior (GEPES) do Departamento de Educação da UNESP, Câmpus de Rio Claro, vinculado ao CNPq. E-mail: maria.boverio@fatec.sp.gov.br

III Docente do Curso Superior em Agronegócio, Produção Industrial, Sistemas para Internet e Análise e Desenvolvimento de Sistemas, Fatec Taquaritinga, São Paulo, Brasil, e-mail: katia.galati@fatectq.edu.br
} 


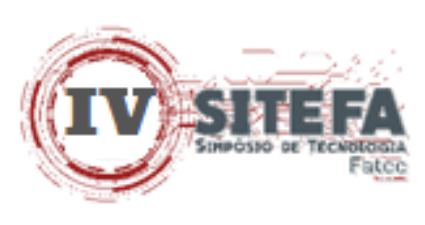

the importance of the status of different elements in the rural landscape and, depending on the degree of vulnerability intensity, mitigating attitudes need to be implemented to ensure the sustainability of the environment and production systems in those areas. The present study aimed to visually assess the environmental vulnerabilities of a given sample area, located in a high area of Taquaritinga hydrographic basin - SP - Brazil, through observation of satellite images of the free software Google Earth Pro. The results showed that the use of Google Earth Pro tools allows to determine with relative precision the elements of the landscape, and to infer a degree of vulnerability of the region under study. Through the satellite images, it was verified that the activity of occupation of the soil has predominance of the culture of the sugarcane ( $71 \%$ of the area). Regarding the vegetation cover, it was found that the permanent preservation areas (PPA) corresponded to $4.50 \%$ of the sampled area. It was also found that the areas of legal reserve (LR) were rarefied, as well as the presence of water surface and the human presence in the rural environment, determined by the few rural constructions in the sampled area. The data suggest a greater attention from the public authorities in the sense of making a planned intervention to mitigate the visually ongoing vulnerabilities, mainly due to the fact that the area is over a recharge area of the Bauru aquifer.

Keywords: Environmental risk. Geotechnologies. Rural landscape. Landscape elements risk.

Data de submissão do artigo: 22/06/2021

Data de aprovação do artigo: 26/10//2021.

DOI: $10.33635 /$ sitefa.v4i1.169

\section{INTRODUÇÃO}

Uma bacia hidrográfica caracteriza-se, essencialmente, por um curso hídrico principal, o qual vai recebendo a inserção de seus afluentes, e que nas partes mais elevadas é delimitada por um divisor de águas e, dentro desse espaço, ocorrem processos de escoamento, de transporte de sedimentos, os quais podem ocasionar impactos sobre a qualidade da água, e o uso e ocupação do solo podem exercer diferentes modificações nessa paisagem. Entretanto, dentro dessa unidade hidrológica existe diversas ações positivas ou negativas, que podem, também, influenciar diretamente no grau de vulnerabilidade a que essa bacia pode estar sujeita (LANNA, 2000; SARTOR et al., 2018; SILVA et al.,2018).

A bacia hidrográfica é uma área topograficamente definida pela drenagem de um canal fluvial ou por um sistema de canais fluviais conectados, de tal forma que toda água drenada nesse espaço tenha uma única saída, e cada bacia hidrográfica pode ser subdividida em bacias menores (microbacias), o que significa dizer que uma bacia hidrográfica é formada por um conjunto de pequenas bacias (ROSA et al., 2004; SILVA et al.,2018).

A degradação dos recursos hídricos superficiais, o conhecimento da disponibilidade de reservas hídricas subterrâneas e o processo desordenado de urbanização, são realidades de bacia hidrográficas que estão ligados diretamente as crises associadas ao sistema de abastecimento de água. As águas subterrâneas podem, de certa forma, se apresentar como um recurso estratégico para aliviar o agravamento da chamada crise hídrica numa dada condição temporal. $\mathrm{O}$ desconhecimento de fato da quantidade de poços profundos outorgados numa dada bacia hidrográfica está longe de estar sob controle dos gestores públicos (MONÇÃO \& VELOSO, 2021) 


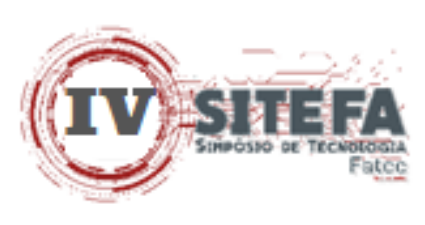

A ação antrópica tem sido atribuída como a causa mais marcante da contaminação das águas subterrâneas, contaminação esta que pode ser intensificada em virtude das características físicas inerentes dos aquíferos, e do uso e ocupação do solo da bacia hidrográfica (ANJINHO et al., 2018). Estes autores relatam ainda que a bacia do rio São Roque (UGRHI 09), no Estado de São Paulo, encontram-se de maneira geral, em estado de vulnerabilidade ambiental em $66,17 \%$ do território da bacia, considerada então por risco de contaminação muito alto. A presença de áreas de proteção ambiental e o manejo do solo com práticas conservacionistas, de modo planejado, propicia a mitigação dos problemas de contaminação e preservação dos mananciais subterrâneos.

Almeida (2010) aborda e amplia o conceito de vulnerabilidade, em que relata a existência e uma coincidência muito grande entre vulnerabilidade social em ambientes urbanos e as regiões vulneráveis na bacia, onde a população está exposta a maiores riscos de inundação, riscos esses que estão muito ligados a fatores de expansão urbana e a impermeabilização do solo. Aborda, ainda, que as áreas de risco em áreas de preservação permanente (APP) em ambiente urbano (encostas, represas, APPs urbanas etc.), notadamente muito comum de ocupação por populações em condições sociais precárias, pode ser melhorada através de planejamento e políticas urbanas consistentes.

O conceito de vulnerabilidade ambiental é um conceito amplo e dinâmico, pois envolve variações do espaço físico de acordo com as paisagens de cada ambiente. Varia entre e dentro dos espaços físicos, por particularidades de cada ambiente ou bioma. Pode variar em relação ao tempo, pois pode haver momentos de maior ou menor intensidade em que determinados fenômenos naturais ocorram. Pode ser resultado de interferências antrópicas no espaço rural e urbano (COSTA, 2018), e que pode ser agravado pelas condições geomorfológicas da região e, ainda, de acordo com as características das atividades econômicas exercidas por diversos segmentos das atividades humanas, principalmente aquelas que se utilizam dos recursos naturais (CANDIDO et al., 2010). Assim, o objetivo desse estudo é avaliar visualmente as vulnerabilidades ambientais de uma dada área amostral, localizada em área alta da bacia hidrográfica de Taquaritinga - SP - Brasil, através de observação de imagens de satélite do software livre Google Earth Pro. O tema se torna relevante, inclusive, pelo fato de a área estar sobre uma área de recarga do aquífero Bauru.

\section{REVISÃO BIBLIOGRÁFICA}

A determinação da vulnerabilidade ambiental de uma paisagem definida no espaço geográfico possibilita a avaliação das condições de risco da área em questão a processos geoambientais, tais como a erosão, contaminação dos solos, dos recursos hídricos, perda de aproveitamento agrícola, dentre outros (KEMERICH; RITTER; BORBA, 2014). Esses autores explicam, ainda, que os comitês de bacia hidrográficas, embora recentes, caracterizam-se por uma representação tripartite da sociedade, que nos idos de 1996 aventouse pelo uso e cobrança da água. Destacam, também, que as características físicas do solo, textura e porosidade, influenciam sobremaneira na infiltração da água no solo e na vulnerabilidade da bacia hidrográfica. O uso e ocupação do solo exercem um papel significativo no agravamento de uma vulnerabilidade natural da bacia.

Morais e Carvalho (2013) inferem que paisagem aparentemente pode ser considerada estática, mesmo numa escala temporal diferente, mas na verdade ela é dinâmica. Atuam sobre os elementos da paisagem vários tipos de forças, podendo ser antrópicas, notadamente pelo uso e ocupação do solo, pelo sistema de ocupação e exploração do espaço geográfico, e que 


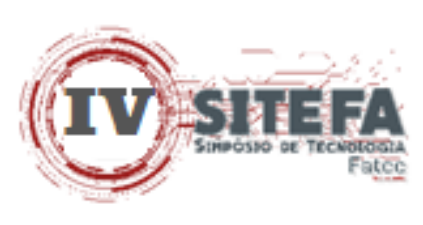

dependendo do grau de intensidade pode influenciar na exposição a maiores vulnerabilidades. Pode, inclusive, atuar na paisagem forças geoambientais que modelam o relevo e hidrografia. De acordo com esses autores as transformações da natureza ocorrem em função da satisfação de necessidades de uma sociedade e, muitas vezes, é de forma contínua. Tal situação, quando intensa e de maneira exacerbada, pode impactar severamente os sistemas naturais. A paisagem vai perdendo suas características essenciais e a sua resiliência natural, ou seja, a capacidade de se recompor fica debilitada.

Nessa mesma linha de pensamento Kemerich, Ritter e Borba (2014), reforçam a ideia de que a bacia hidrográfica é uma unidade básica para quaisquer tipos de estudos ambientais, e na avaliação ambiental, deve-se obedecer a critérios técnicos e alicerça-se por um planejamento adequado, além de conhecer detalhadamente as características naturais do ambiente, por exemplo, elaborar mapeamentos das vulnerabilidades bem detalhados. Assim, pode-se evitar o aumento do grau de vulnerabilidade ambiental dentro de uma determinada bacia hidrográfica, dando a ela usos compatíveis com o seu estado atual. Nesse sentido, diagnosticar os fatores que estão desencadeando o quadro de vulnerabilidade ambiental numa dada bacia é primordial para depois buscar alternativas de remediação mais eficazes.

O uso de geotecnologias tem permitido estudos consistentes sobre vulnerabilidade de uma bacia hidrográfica, conforme relatos de Cândido et al. (2010). Nesse aspecto, esses autores estudaram as vulnerabilidades da bacia do rio Uberaba, em MG, e constataram que mais que a metade da área da bacia apresentava grau de severidade de ação antrópica variando de "acentuado a severo". $\mathrm{Na}$ análise da vegetação da bacia do estudo ficou evidente a presença de cobertura vegetal bastante rarefeita, o que denota uma das vulnerabilidades marcantes no estudo, as quais estão intimamente associadas a ações antrópicas negativas, resultado de processos de degradação das terras (LANNA, 2000; CANDIDO et al., 2010). A topografia e a cobertura vegetal natural podem exercer um papel preponderante nos processos de degradação ambiental (MORAIS; CARVALHO, 2013; KEMERICH; RITTER; BORBA, 2014), ou seja, a combinação de áreas declivosas associadas com vegetação natural nativa rarefeita potencializam os processos erosivos, e, consequentemente, determinam uma maior vulnerabilidade ambiental.

O uso de ferramentas de geotecnologias permite identificar e mapear as características geoambientais e as vulnerabilidades natural e ambiental de uma determinada bacia hidrográfica e, através de políticas públicas consistentes e a gestão ordenada de bacias hidrográficas (MORAIS; CARVALHO, 2013), envolvendo os diversos atores, pode-se mitigar o processo de vulnerabilidade em curso (COSTA, 2018). No estudo de Costa (2018) verificou-se que as áreas que eram anteriormente consideradas preservadas vêm permitindo avanço para o crescimento de culturas anuais ou perenes, e mesmo culturas de ciclo curto, de tal sorte que tais ações antrópicas, pelo uso e conservação do solo de modo inapropriado (MORAIS; CARVALHO, 2013; COSTA, 2018), mudaram significativamente a paisagem local, o que é facilmente observável pelas imagens de satélite, mesmo em áreas próximas aos centros urbanos, motivadas pela expansão urbana desordenada.

\section{PROCEDIMENTOS METODOLÓGICOS}

O estudo foi realizado na região mais alta da bacia hidrográfica de Taquaritinga, SP, de Latitude $21^{\circ} 22^{\prime} 13.60^{\prime \prime S}$ e longitude $48^{\circ} 26^{\prime} 30.02^{\prime \prime O}$, à qual pertence ao Conselho de Bacia Hidrográfica Tietê- Batalha do Estado de São Paulo. Tal região de estudo faz parte dos resultados de diagnóstico na referida bacia hidrográfica, conduzido por Rodrigues, Carleto e 


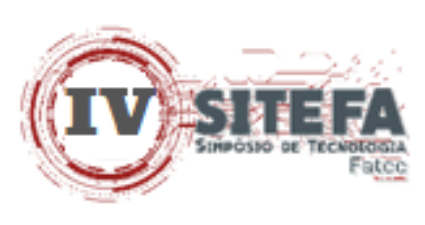

Santos (2020). A cidade de Taquaritinga tem aproximadamente 57.364 habitantes e distante de São Paulo $372 \mathrm{~km}$, e de Ribeirão Preto $90 \mathrm{~km}$ (SANTOS, 2016). Para o estudo foi designada uma área amostral de aproximadamente 4000ha, na forma de um círculo, realizada com o uso do software livre Google Earth Pro, da ferramenta "linha", na aba "círculo", e a área em destaque (Figura 1- Quadrante 1, Q1) foi dividida em 4 quadrantes (Q1, Q2 Q3 e Q4), utilizando as ferramentas do Google Earth Pro, tal como usada no trabalho de Rodrigues, Ferrarezi e Bovério (2020). A Figura 1 mostra a área principal de estudo, e em destaque colorido os elementos da paisagem do Quadrante 1, para a realização desse trabalho preliminar.

Os elementos da paisagem rural a serem identificados no referido quadrante constou da quantificação de área carreadores (CA), área impermeável (AI), área de preservação permanente (APP), áreas de Construção (AC), áreas de culturas lenhosas (CL), área de Superfície de Lâminas d'Água (LD) e áreas de culturas semi-perenes (CSP). Para a quantificação dessas áreas foram feitas o uso da ferramenta "polígono", em que se tem a informação de perímetro e área de cada um dos elementos da paisagem, das respectivas áreas. A ferramenta "caminho" foi utilizada especificamente na medição dos comprimentos dos elementos carreadores e a área impermeável, a qual corresponde a área de domínio de estrada asfaltada nesse quadrante.

Para o cálculo da área de solo descoberto, considerou-se os vários tipos de carreadores no quadrante, os quais apresentam larguras variáveis. Para tanto, amostrou-se 10 larguras ao acaso dos carreadores presentes no devido quadrante utilizando-se do comprimento total dos carreadores, multiplicado pela largura média dos carreadores e estimou-se a área provável desprovida de solo em área propriamente agrícola. As áreas de asfaltamento obedeceram a mesma lógica. Uma vez que foram determinados os comprimentos de toda área asfaltada no quadrante, a área deste foi resultado da multiplicação do comprimento da malha asfáltica pela largura do pavimento. As áreas de Preservação Permanente (APP), áreas de Construção (AC), áreas de Culturas Lenhosas (CL), áreas de Lâminas d'Água (LD) foram determinados o perímetro e a área diretamente. As Culturas Semi-perenes (CSP), representadas pela cultura da cana-de-açúcar, foi determinada pela subtração da área total do quadrante e de todos os elementos da paisagem rural. 
Figura 1 - Área amostral da região nordeste (quadrante 1) da região mais alta da bacia hidrográfica de Taquaritinga

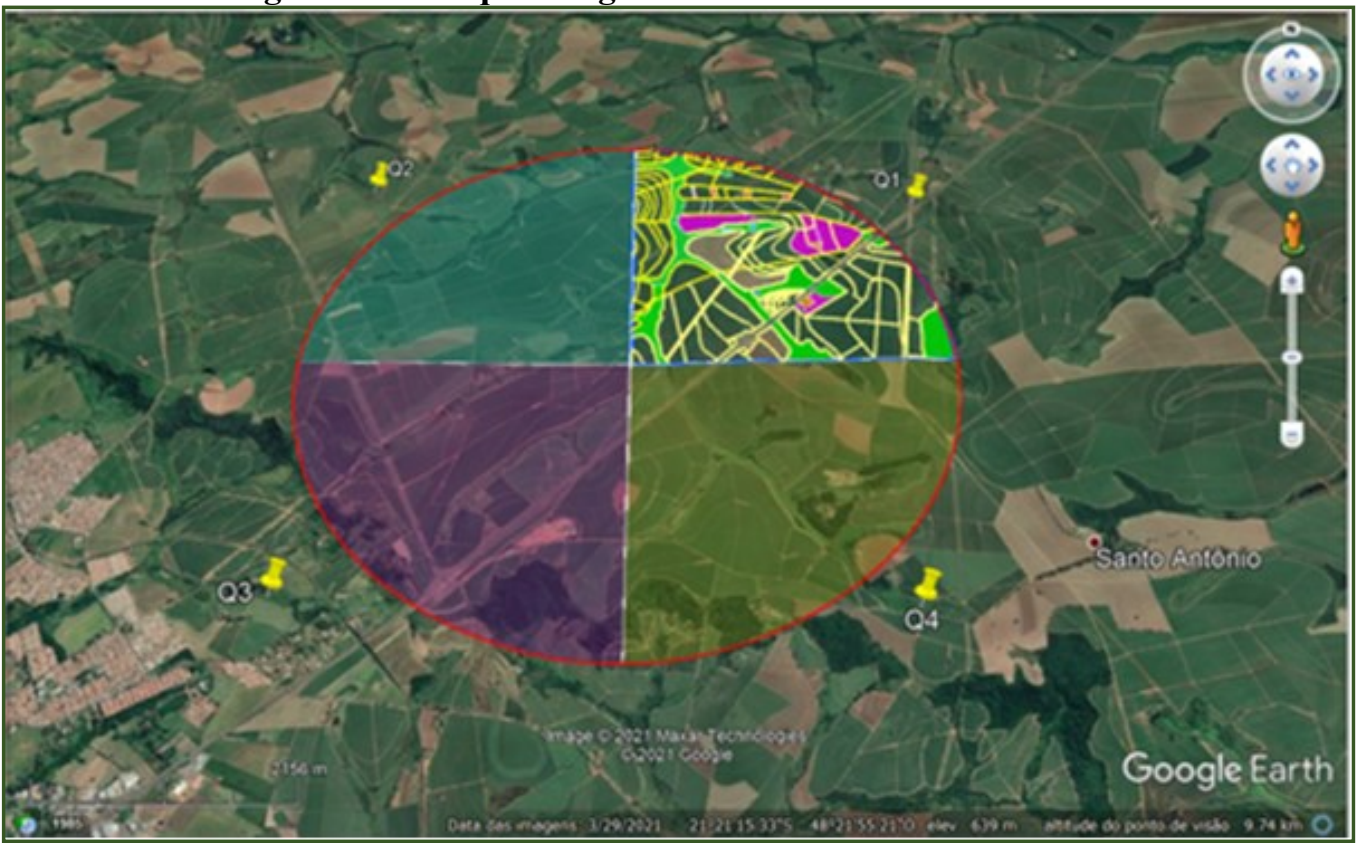

Observações: áreas de APP (em verde claro), áreas de culturas lenhosas(roxo) e áreas de construção rural (laranja) da parte mais alta da bacia hidrográfica de Taquaritinga

Fonte: os autores (2021) com o uso do software livre Google Earth Pro em março de 2021

Figura 2 - Área amostral da região nordeste (Quadrante 1) com destaque para três elementos da paisagem

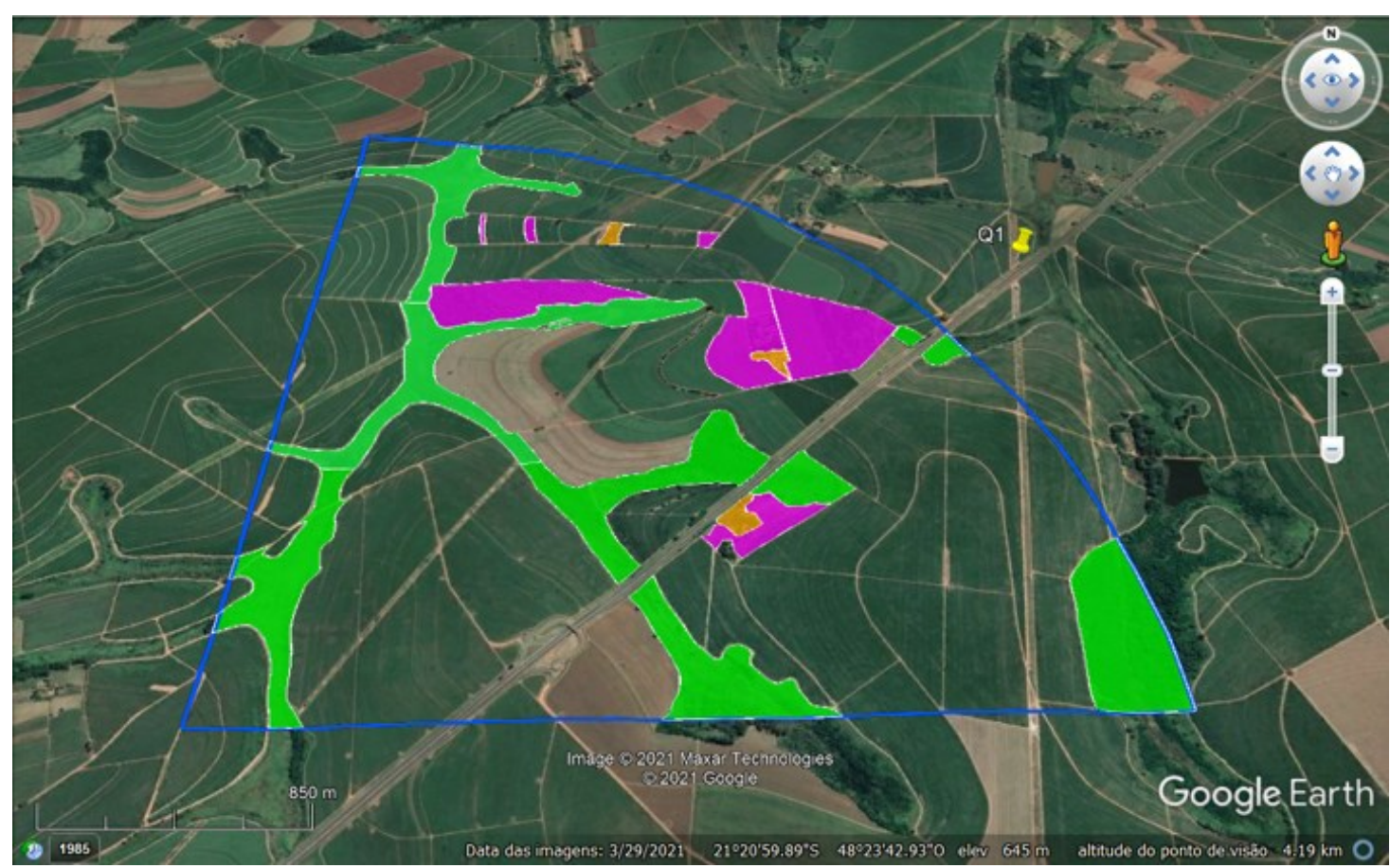

Observações: áreas de APP (em verde claro), áreas de culturas lenhosas(roxo) e áreas de construção rural (laranja) da parte mais alta da bacia hidrográfica de Taquaritinga

Fonte: os autores (2021) com o uso do software livre Google Earth Pro em março de 2021 
Para a organização das informações contabilizadas utilizou-se o software Excel para organização dos dados mensurados em hectare quando correspondendo a área, e elaboração das porcentagens de cada elemento da paisagem em relação a área total do quadrante.

\section{RESULTADOS E DISCUSSÃO}

Os resultados da quantificação dos elementos da paisagem rural possíveis de quantificação são apresentados no Gráfico 1. Constata-se que os quatros elementos mais expressivos na paisagem correspondem à cultura da cana de açúcar $(\mathrm{CSP}=71 \%)$, seguido por áreas de preservação permanente $(\mathrm{APP}=15 \%)$ e culturas lenhosas $(\mathrm{CL}=7 \%)$ e carreadores $(\mathrm{CA}=5 \%)$. Não foi verificada neste quadrante áreas que se caracterizassem claramente por áreas de reserva legal (RL).

Uma vez que a área total desse quadrante corresponde 895 ha, de acordo com o novo código florestal, as áreas destinadas à reserva legal (RL) deveriam corresponder à $20 \%$ da área do quadrante, ou seja, 172 ha. Portanto, nota-se que as áreas de reserva legal são rarefeitas indicando uma possível ocupação por áreas de produção agrícola e carreadores. Além disso, constata-se que as áreas de carreadores são aparentemente bem representativas nesse quadrante, podendo-se inferir que as áreas de carreadores somadas às áreas de cana de açúcar perfazem um total de 772 ha(86\%), possivelmente devido ao predomínio da área de cana-de-açúcar nesse quadrante, sugere a necessidade uma redução de número talhões pois são numerosos, e a vizinhança da cultura da cana-de-açúcar com as áreas de APP são margeadas por carreadores, os quais pode vir a ser um facilitador para o tráfego necessário para monitoramento do ciclo da cultura predominante na respectiva área.

Gráfico 1 - Quantidades totais em (ha) e porcentagem (\%) de cada elemento da paisagem identificados no quadrante 1

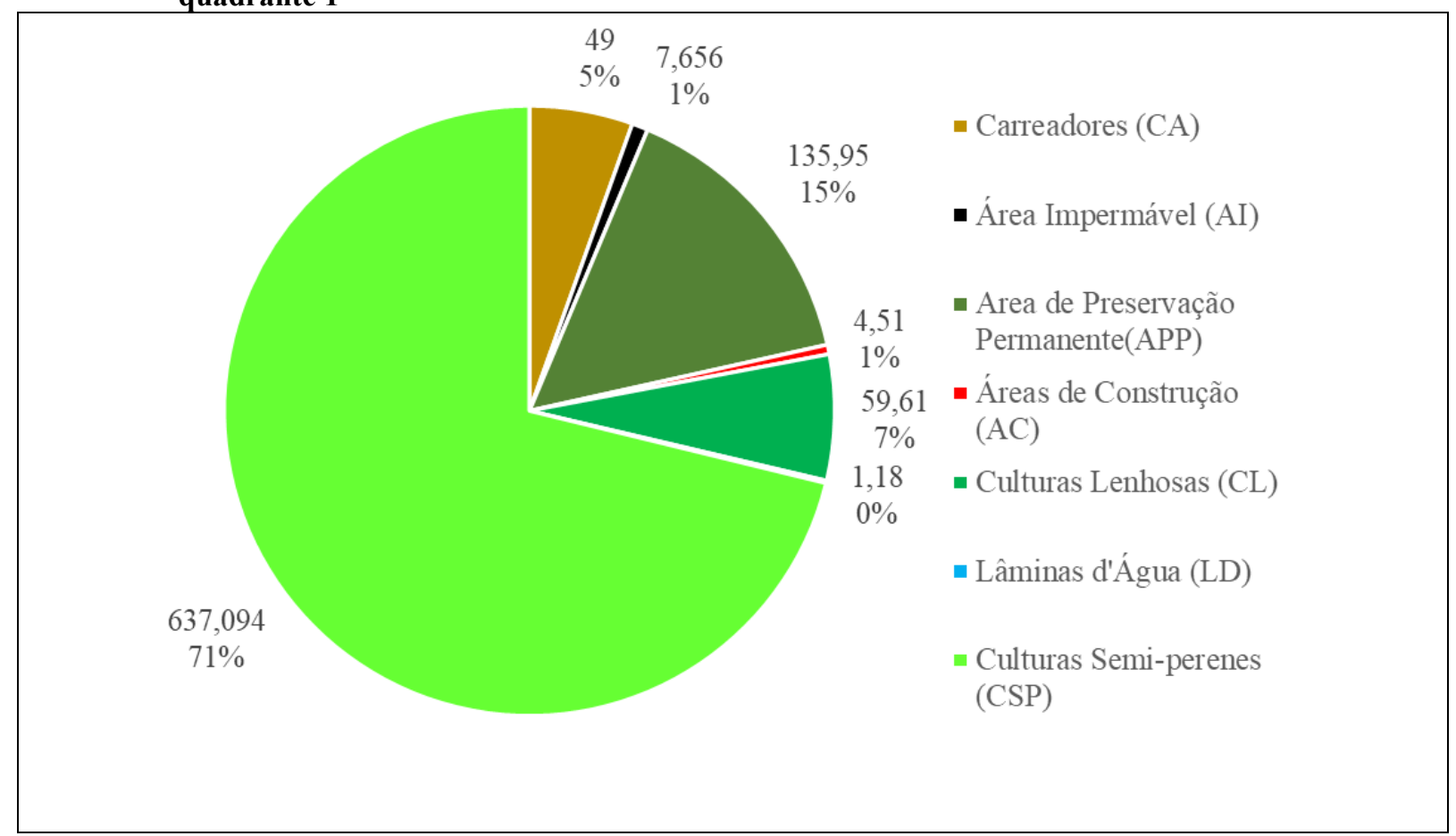

Fonte: os autores (2021) com o uso do software livre Google Earth Pro em março de 2021 


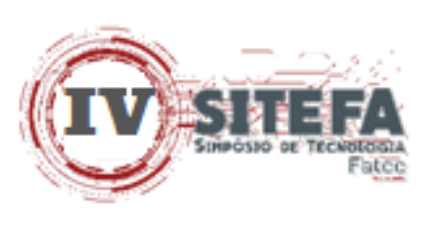

Assim, verifica-se que o déficit de áreas de reserva legal provavelmente é ocupado nesse quadrante por áreas de cana-de-açúcar e carreadores, deixando o respectivo quadrante em dissonância com o código florestal. A relação de área de carreadores para área de cana-deaçúcar é de 1: 4,68, o que permite inferir que a área de carreadores e CSP poderiam ter uma redução próxima de $25 \%$, e isso faria com que houvesse uma adequação do espaço muito próximo para a atender a legislação ambiental quanto a manutenção de RL.

De acordo com Costa (2018), aprofundar as discussões sobre o ordenamento territorial do espaço geográfico é de suma importância para promover o planejamento local e regional, a partir de planos diretores municipais e comitês de bacias de cada estado. Dessa forma com bom planejamento é possível promover a sustentabilidade ambiental de uma dada região, para que ela atenda às necessidades de sustentabilidade do sistema de produção e, ao mesmo tempo, a preservação dos recursos naturais. O autor ressalta, ainda, que o uso de ferramentas de geotecnologias é balizador de políticas públicas e de gestão de bacias hidrográficas e, dessa maneira, pode contribuir para o desenvolvimento local e regional.

De acordo com Morais e Carvalho (2013), a associação entre os aspectos de uso e cobertura da terra, com parâmetros conceituais de paisagem, mostram uma importância para focar e direcionar um conjunto de ações que norteiam, de fato, a gestão do espaço territorial rural e urbano que, muitas vezes, é comum verificar a diferença de interesses e, por isso, pode gerar conflitos. De acordo com esses autores, o grau de conectividade da paisagem é um dado importante para avaliar o grau de fragmentação da paisagem, ou seja, menor fragmentação indica maior conectividade entre os hábitats, o que provavelmente resulta numa maior e melhor mobilidade da fauna e flora através da paisagem.

Nesse estudo preliminar, com uma área que representa 895 ha é um indicativo de como os elementos da paisagem se encontram e, futuramente, na conclusão da avaliação de todos os elementos visuais de toda área amostral, pretende-se fornecer subsídios mais consistentes para a adoção de atitudes mitigatórias como, por exemplo, a reordenação dos elementos da paisagem, em particular os carreadores e áreas de RL.

É possível constatar pelas imagens de satélite que em áreas com predomínio de afastamento, há uma preocupação com a conservação do solo e água, com a presença de bacias de contenção, paralelo à rodovia. Nota-se, também, que em parte da área agrícola dominada pela cana-de-açúcar, há uma quantidade expressiva de bacias de contenção, uma prática conservacionista que evita a erosão e auxilia na captação e infiltração da água no solo. Vale a pena destacar que as áreas de baixada nesse espaço avaliado, consideradas áreas de APP, não ficam evidentes pelas imagens de satélite a visão dos pequenos cursos d'água, e vêse o predomínio de forrageiras perenes do Gênero Panicum, Echinochloa(Brachiaria), Pennisetum, Andropogon bicornis (Capim rabo de burro) e Paspalum virgatum (Navalha de macaco) (ANDRADE, 2015; ANDRADE; FONTES, 2015), e pouca densidade e diversidade de espécies arbustivas nativas, com predomínio de Embaúba (Cecrópia spp.) e Sangra d'água (Croton spp.), (PRATA; PINTO; ASSIS, 2011). A baixa densidade de espécies nativas nas áreas de APP sugere uma diversidade biológica limitada de essências nativas arbustivas.

A área sob estudo tem o predomínio da cultura da cana-de-açúcar, com colheita mecanizada que vem contribuindo para amenizar os processos erosivos e assoreamento nas áreas de proteção ambiental. Segundo os estudos de Sousa, Martins Filho e Matias (2012), a cobertura do solo com palha de cana-de-açúcar acima de $50 \%$, da área colhida propicia a redução da perda de solo e de matéria orgânica, e muito provavelmente contribui para diminuir a concentração de nutrientes, eventualmente no sedimento que é naturalmente erodido. A dose de até $15 \mathrm{t} \mathrm{ha}^{-1}$ de palha de cana-de-açúcar sobre o solo pode diminuir a 


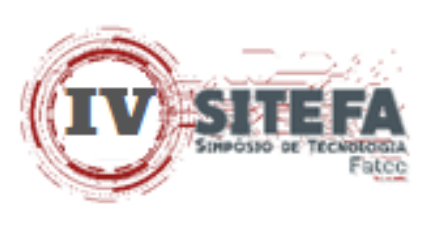

velocidade de degradação dos nutrientes na palhada, e o incremento de palha sobre o solo pode melhorar os atributos físicos do solo, principalmente em solos arenosos, por contribuir e atenuar a compactação do solo, principalmente em solos argilosos, e presume-se que a retirada de palha para fins industriais possa ser mais prejudicial em solos arenosos. (SANTOS, 2016).

A área sob estudo preliminar tem como ponto positivo o predomínio da presença da palha da cana-de-açúcar na superfície do solo, devido a colheita mecanizada, o que reduz as perdas de água significativamente comparado à condição de solo descoberto, que tem perdas de água muito mais por evaporação (PERES; SOUZA; LAVORENTI, 2010), enquanto áreas com cobertura de palha, a água tem capacidade de infiltração em camadas mais profundas, e pode contribuir positivamente no longo prazo para a recarga do aquífero associado ao incremento de áreas de contenção de água da chuva (Bacias de contenção).

A palha sobre o solo é um fator positivo na manutenção da microfauna e macrofauna do solo da área sob estudo preliminar, além de poder amenizar os impactos da perda de solo. Segundo Arana et al. (2017), pode-se inferir que os agroquímicos mais utilizados no cultivo da cana-de-açúcar interferem nos parâmetros funcionais de comunidades piscícolas do Estado de São Paulo. Tais moléculas complexas tem a capacidade de comprometer sistemas orgânicos do ecossistema aquático, chegando a interferir principalmente no processo reprodutivo de seres que são muito sensíveis as variações do meio.

Nocelli et. al. (2017), relatam que as áreas de cana-de-açúcar com diferentes graus de impacto ambiental têm propiciado que aves e outros organismos, os insetos por exemplo, presentes nas áreas de cultivo e em seu entorno, podem, por diferentes meios, ficar vulneráveis aos vários sistemas de manejo da cultura. A determinação do real impacto sobre aves e insetos não é de fácil mensuração, mas tais impactos existem e devem ser avaliados, e o quanto possível minimizados para garantir o retorno do equilíbrio e a conservação desses ecossistemas, uma vez que constata-se que em áreas de cana-de-açúcar, as espécies mais comuns de aves avistadas eram aves generalistas e especialistas de borda de fragmentos florestais, o que pode ser considerado situação de alta vulnerabilidade, daí ressalta-se a importância de conexão de corredores de áreas de preservação ambiental.

\section{CONCLUSÃO}

Por meio do software livre Google Earth Pro foi possível identificar com clareza as vulnerabilidades ambientais de parte de uma área amostral, da região mais alta da bacia hidrográfica de Taquaritinga-SP, em particular as áreas de preservação permanente, que se mostram numericamente abaixo do requerido no código florestal.

As imagens do software Google Earth Pro permitiram verificar os diferentes usos e ocupação do solo, caracterizado pelo predomínio da cultura de cana-de-açúcar, seguido por culturas lenhosas, e a presença de palha sobre o solo, bacias de contenção em pequena quantidade e curvas de nível como práticas conservacionistas do solo e água bem estruturada. Outro elemento da paisagem rural que se destacou na avaliação visual foi a área destinada a carreadores muito próximo da área destinada a culturas lenhosas.

O trabalho preliminar ressalta que a área em questão pode ser motivo de planejamento para recomposição florestal, com o objetivo de aumentar a infiltração de água no solo e preservar os mananciais subterrâneos. Um reordenamento das áreas de produção agrícola, dominada por cana-de-açúcar, diminuindo o número e área destinada a carreadores diminuirá a área de solo exposto, reduzindo assim eventuais perdas de solo e matéria orgânica. Outra 
vulnerabilidade ambiental marcante nesse quadrante é a aparente ausência de reserva legal e áreas de preservação permanente (APP) com pouca densidade arbórea, as quais podem estar limitando a diversidade, manutenção e dispersão da flora e fauna local.

\section{REFERÊNCIAS}

ALMEIDA, L. Q. de Vulnerabilidades socioambientais de rios urbanos: bacia hidrográfica do rio Maranguapinho, região metropolitana de Fortaleza, Ceará. 2010. 278p. Tese (doutorado) - Universidade Estadual Paulista, Instituto de Geociências e Ciências Exatas- Rio Claro, 2010, 278p.

ANDRADE, C. M. S. de; FONTES, J. R. A. Biologia e manejo de capim-navalha e capimcapeta em pastagens. Cap. 4, p. 71, 2015. In: IKEDA; INOUE. Manejo Sustentável de Plantas Daninhas em Sistemas de Produção Tropical. Embrapa Brasília, DF, 2015, 121p.

ANDRADE, C. M. S. de Controle do capim-navalha com enxada química manual. Folders, EMBRAPA Acre, 2015. Disponível em: https://www.embrapa.br/busca-de-publicacoes//publicacao/1029521/controle-do-capim-navalha-com-enxada-quimica-manual. Acesso em: 10 mar. 2021.

ANJINHO, P. da S.; CAMPOS, L. G.; MAUAD, F. F.; MOSCHINI, L. E. Geotecnologias aplicado à análise do risco à contaminação dos aquíferos da bacia hidrográfica do rio São Roque - SP. Águas Subterrâneas - Seção Estudos de Caso e Notas Técnicas,11p., 2018. http://dx.doi.org/10.14295/ras.v32i3.29136

ARANA, S.; ANSOAR-RODRÍGUEZ, Y.; GUEDES, T. de A.; MARCATO, A. C. de C.; CORREIA, J. E.; FONTANETTI, C. S. Peixes como bioindicadores do impacto no ambiente aquático induzido por agrotóxicos empregados no cultivo da cana-de-açúcar, Cap. 12, p. 229 250. Bauru, SP: Canal 6, 2017. 275 p. In: FONTANETTI, C.S.; BUENO, (org.). O. C. Canade-açúcar e seus impactos: uma visão acadêmica. 2017.

CANDIDO, H. G., GALBIATTI, J. A., PISSARRA, T. C. T., MARTINS FILHO, M.V. Degradação ambiental da bacia hidrográfica do rio Uberaba: uma abordagem metodológica Eng. Agríc., Jaboticabal, v.30, n.1, p.179-192, jan./fev. 2010.

COSTA, Franklin Roberto da. Análise da Vulnerabilidade Ambiental da Bacia Hidrográfica do Rio Doce (RN). 2018.244p. Tese (Doutorado) - Universidade Federal do Rio Grande do Norte. Centro de Biociências RN, Natal, 2018. 244 p.

KEMERICH, P. D. da; RITTER, L. G.; BORBA, W. F. de Vulnerabilidade ambiental e áreas de infiltração máxima de água. Revista Monografias Ambientais - REMOA, v. 13, n. 5 (2014): Edição Especial LPMA/UFSM, p. 3761-3776.

LANNA, A. E. A inserção da gestão das águas na gestão ambiental, in interfaces da gestão de recursos hídricos desafios da lei de águas em 1997, Ministério do Meio Ambiente - MMA, p. 77 - 109, Brasil, 2000. 


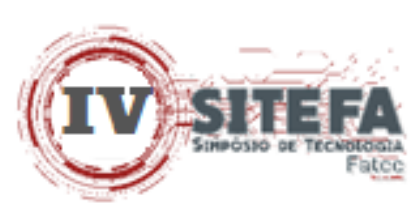

MONÇÃO, A. G. \& VELOSO, R. B. A importância das águas subterrâneas para a gestão integrada dos recursos hídricos: captação, controle e monitoramento na bacia do rio Verde Grande. Águas Subterrâneas - Seção Estudos de Caso e Notas Técnicas,11p., 2021 http:/dx.doi.org/10.14295/ras.v35i1.30026

MORAIS, R. P.; CARVALHO, T. M. de. Cobertura da terra e parâmetros da paisagem no munícipio de Caracaraí -Roraima Rev. Geogr. Acadêmica v.7, n.1, 2013, p. 46 - 59.

NOCELLI, R. C. F.; PIRES, C.; TOREZANI, K.; CIONE, A. P.; SHIWA, A.; TONELLI, C.; MARCONDES, C.; BELCHIOR, C.; VIANA-SILVA, F.; GUIMARÃES, G.; TEIXEIRA, I.; CHAM, K.; BORGES, L.; MALASPINA, O. Matrix of selection for Brazilian bee species to risk assessement. In: INTERNATIONAL SYMPOSIUM HAZARDS OF PESTICIDES TO BEES, 13., 2017, Valencia. [Abstracts...] Ontario: International Commission for Plant Pollinator Relationships (ICPPR), 2017. Biblioteca(s): Embrapa Recursos Genéticos e Biotecnologia.

PERES, J. G.; SOUZA, C. F.; LAVORENTI, N. A. Avaliação dos efeitos da cobertura de palha de cana-de-açúcar na umidade e na perda de água do solo. ENG. AGRÍC., Jaboticabal, v.30, n.5, p.875-886, set./out. 2010

PRATA, E. M. B.; PINTO, S. dos A. F.; ASSIS, M. A. Fitossociologia e distribuição de espécies arbóreas em uma floresta ribeirinha secundária no Município de Rio Claro, SP, Brasil. Revista Brasil. Bot., v.34, n.2, p.159-168, abr.-jun. 2011

RODRIGUES, G. A.; CARLETO, N.; SANTOS, G. O. Geração um de mapa hipsométrico da bacia hidrográfica de Taquaritinga/SP. Revista Interface Tecnológica, [S. l.], v. 17, n. 1, p. 492-504, 2020. https://doi.org/ 10.31510/infa. v17i1.824.

RODRIGUES, G. A.; FERRAREZI, L. A; BOVÉRIO, M. A. Metodologia para determinação da abundância de árvores urbanas utilizando recursos de geotecnologias de acesso livre.

Journal of Biotechnology and Biodiversity, v. 8, n. 3. 2020, p172-178. Disponível em: https://doi.org/10.20873/jbb.uft.cemaf. Acesso em: 30 mar. 2021

ROSA, R., BRITO, J. L. S., LIMA, E. F., SIQUEIRA, C. A., MACEDO, D. Elaboração de uma base cartográfica e criação de um banco de dados georreferenciados da Bacia do Rio Araguari - MG. In: Gestão ambiental da bacia do Rio Araguari - rumo do desenvolvimento sustentável. LIMA, S. C., SANTOS, R. J. (org.). Uberlândia, Universidade Federal de Uberlândia, Instituto de Geografia; Brasília: CNPq, 2004, p. 69-88.

SANTOS, A. P. G. Manutenção da palha em superfície e seu efeito nos atributos do solo e na produtividade do canavial, 2016, 159 p. Tese(doutorado), Faculdade de Engenharia Agrícola da Universidade Estadual de Campinas, UNICAMP, Campinas, 2016.

SANTOS, WILLIAM SILVA dos. Diagnóstico 2018 / Secretaria de Esporte, Cultura, Turismo e Lazer; [organização] Taquaritinga, SP: Ed. do Autor, 2018, 93p. https://www.al.sp.gov.br/spl/2019/02/Acessorio/1000254248_1000235273_Acessorio.pdf Acesso em: 19.06.2021. 
SARTOR, M. B.; PIZA, M. W. de T.; SILVEIRA, G. R. P. da; AZEVEDO, E. P. G. \& CAMPOS, S. Caracterização física da bacia hidrográfica do córrego da lontra - Cafelândia, SP. ENERGIA NA AGRICULTURA, 33(1), 58-65, 2018.

https://doi.org/10.17224/EnergAgric.2018v33n1p58-65

SILVA, G. C. da; ALMEIDA, F. de P.; ALMEIDA, R. T. S.; MESQUITA, M. \& ALVES JUNIOR, J. Caracterização morfométrica da bacia hidrográfica do riacho Rangel, Piauí, Brasil. ENCICLOPÉDIA BIOSFERA, Centro Científico Conhecer - Goiânia, v.15, n.28, p. 244-258, 2018.

SOUSA, G. B.; MARTINS FILHO, M. V.; MATIAS, S. S. R. Perdas de solo, matéria orgânica e nutrientes por erosão hídrica em uma vertente coberta com diferentes quantidades de palha de cana-de-açúcar em Guariba - SP. Eng. Agríc., Jaboticabal, v.32, n.3, p.490-500, maio/jun. 2012 